LETTER

\section{Flattening the curve of new publications on COVID-19}

In order to respond to the severe acute respiratory syndrome coronavirus 2 (SARSCoV2) pandemic, all fields of medical and biological sciences are working to improve the understanding of coronavirus disease 2019 (COVID-19). In this race against time, studies are expeditiously conducted and journal review and acceptance processes accelerated. Although this approach dramatically reduced the time required to publish, could the quality of these new studies be affected? Indeed, reducing the review time may allow for errors or biases to be missed, jeopardising the validity of evidence-based medicine principles. Abundance of information can also be confusing for healthcare practitioners and governments. ${ }^{1}$ Moreover, redundancy in COVID-19 trials could lead to lost time and energy for research teams, scientific journals and reviewers. ${ }^{2}$

In order to explore this phenomenon, we used the Medline database to assess the occurrence of the keyword COVID19 along the course of the pandemic. We also extracted data concerning COVID-19 deaths from Worldometer (https://www. worldometers.info/coronavirus/) to obtain the cumulative number of deaths since the first report on 23 January 2020. Death reporting was chosen because it is a more reliable pandemic progression index than the number of cases. Stata 15 (StataCorp, College station, TX, USA) was used for data analysis and graphical representations. The growth rate of deaths and of publications were calculated on the basis of cumulative data.

From 21 January 2020 until 22 April 2020 , a total of 6173 publications using the keyword COVID-19 were identified. During the same period, 184066 COVID19-related deaths were reported. Graphical representation of the cumulative number of publications over time demonstrated a curve similar to that of cumulative number of deaths (figure 1A). The growth rate calculated from the raw cumulative number of deaths and publications demonstrated similar tremendous rates (figure $1 \mathrm{~B}$ ).

We demonstrated that there is an abnormal amount of newly reported studies on COVID-19. It appeared that the amount of publications over time rose earlier than
A

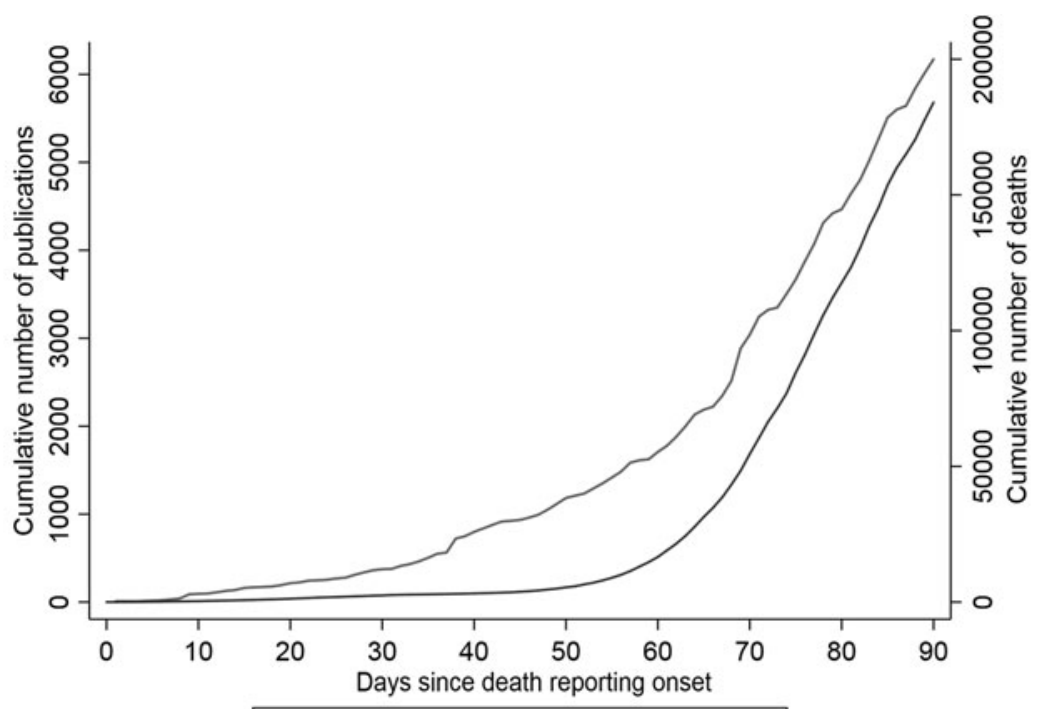

B

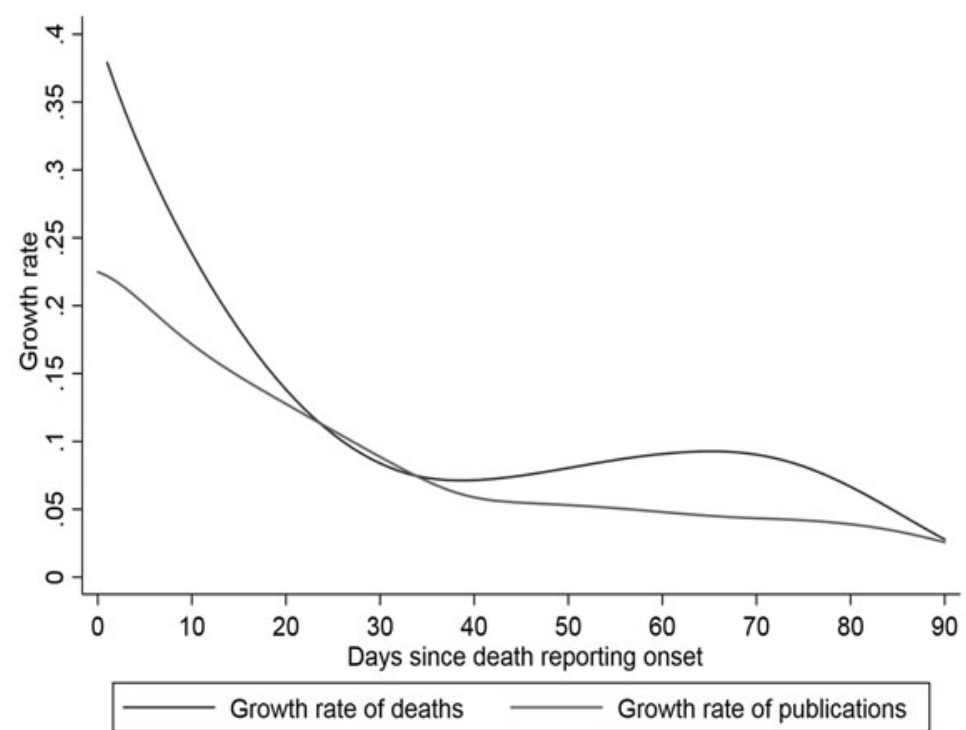

Figure 1 (A) Cumulative number of publications using the keyword COVID-19 on Medline and cumulative number of deaths worldwide plotted against the number of days since the first reported death. (B) Smoothened (non-parametric regression) growth rates of new deaths caused by COVID19 and new publications on this topic. COVID-19, coronavirus disease 2019.

that of deaths and followed a similar growth rate to SARS-CoV2 deaths. A limitation to our analysis was that we were not able to evaluate the level of evidence of the reports. This should be evaluated in a subsequent study.

While acknowledging the academic obligations of institutions and research groups, scientists should be conscious of the impact that these studies may have on designing healthcare policies worldwide. We therefore call for judgement in publishing COVID-19-related studies and call upon scientists worldwide to keep research quality standards unchanged.

\section{Alexandre Balaphas (D) ${ }^{1}$ Kyriaki Gkoufa, ${ }^{2}$ Marie-Josée Daly, ${ }^{3}$ Timothée de Valence ${ }^{3}$}

${ }^{1}$ Division of Digestive Surgery, Geneva University Hospitals, Geneva, Switzerland

${ }^{2}$ Division of Endocrinology, Diabetology, Nutrition and Patient Education, Geneva University Hospitals, Geneva, Switzerland

${ }^{3}$ Division of Acute Medicine, Geneva University Hospitals, Geneva, Switzerland

Correspondence to Alexandre Balaphas, Division of Digestive Surgery, Department of Surgery, Geneva University Hospitals, Geneva, Switzerland; alexandre. balaphas@unige.ch

Received 25 May 2020 Accepted 20 June 2020 
Acknowledgements We would like to thank Prof. Perneger from the Division of Epidemiology of University Hospitals of Geneva for his precious advice. We are also grateful to Mr Michael Daly for language editing.

Contributors All authors fulfill the ICMJE criteria of authorship. $A B, K G, M-J D$ and $T d V$ designed this work; $A B$ and $K G$ collected the data; $A B, K G, M-J D$ and TdV analysed the data, wrote the draft of the manuscript, contributed to critical revisions of the manuscript and approved the final version of the manuscript.

Funding The authors have not declared a specific grant for this research from any funding agency in the public, commercial or not-for-profit sectors.
Competing interests Dr Alexandre Balaphas and Dr Gkoufa are running studies on COVID-19.

Patient consent for publication Patients or the public were not involved in the design, conduct, reporting or dissemination plans of our research.

Provenance and peer review Not commissioned; internally peer reviewed.

This article is made freely available for use in accordance with BMJ's website terms and conditions for the duration of the COVID-19 pandemic or until otherwise determined by BMJ. You may use, download and print the article for any lawful, non-commercial purpose (including text and data mining) provided that all copyright notices and trade marks are retained.

ORCID iD

Alexandre Balaphas http://orcid.org/0000-0001-90396579

\section{REFERENCES}

1 loannidis JPA. Coronavirus disease 2019: the harms of exaggerated information and non-evidence-based measures. Eur J Clin Invest 2020:50:e13222.

2 London AJ, Kimmelman J. Against pandemic research exceptionalism. Science 2020;368:476-7. 